\title{
A year of restoration for Episodes
}

In accordance with the terms of the Memorandum of Understanding (MOU) between the International Union of Geological Sciences (IUGS) and the Ministry of Geology and Mineral Resources of China, the Ministry has assumed responsibility for producing Episodes since the 20 th volume. The first task was to put a new editorial team in place to succeed the team, that had produced the journal in the United Kingdom, to implement the terms of the MOU in an effort to help IUGS better serve the interests of the international community of carth scientists. You, our readers, now have before you the last issue of the 20th volume of the journal, which is also the first volume to have been produced in China. It is perhaps an appropriate time, therefore, to tell you something of what happened to Episodes in 1997 and of our aspirations for it in the years ahead.

IUGS asked us, as a priority, to restore each regular issue of the journal to its original size of about 80 pages (from 48 pages), to restore the journal's four issues per year (from three previously), and to restore its regular publication schedule of March. June, October, and December. This meant, in effect, that in little more than half a year we had to produce a journal twice the size of the immediately preceding ones. It was a challenge for a new, inexperienced editorial team in a nonEnglish speaking country. However, with the help and support of IUGS and its Advisory Board on Publications, and with the help of my British predecessor, Dr. Rodney Walshaw, we have been successful in fulfilling this task in many ways, although we realize we still have some way to go to complete it.

You will understand, therefore, that with these above targets as priorities, the new editorial team had to concentrate in the year of 1997, a year of restoration, on quantity and speed of delivery more than on quality. We realize this, as we realize the distance we have yet to travel to attain all the goals for Episodes that IUGS have set.

Quality is vital for a journal. To improve the quality is by far a more difficult and long term task. We want very much to continue to improve the quality of the submissions to Episodes, particularly as original scientific articles, short notes on important new discoveries, and reviews of topical issues, but we know these are going to be hard to attract until we can improve our refereeing process, widen the journal's subscription-base, and in other ways demonstrate more forcefully that Episodes can be competitive with the better earthscience journals of the world. Such a heavy task can not be met in a matter of a few months. But we intend to make quality our new issue of priority, and the process has already begun with the appointment (now in progress) of a panel of internationally based, well-respected earth scientists as Associate Editors. Their key tasks will be to review the manuscripts of the articles, notes, and reviews mentioned above, to advise on their suitability for publication, and to solicit new original submissions from the world-wide community. You, our readers, can help by continuing to send us your better papers, encouraging others to do the same, persuading your libraries and individual contacts to subscribe to Episodes, and by criticisms and suggestions. Recently, our editorial team has received a criticism for the quality of some figure-reproductions, followed by practical suggestions for improvement, which are very useful for our work in the future. Undoubtedly, with our joint efforts, we can make Episodes a better journal.

Finally, let me apologize for the inconvenience caused to many of our readers through delays in dispatching issues of Episodes to you. We received a validated list of subscribers and other recipients only at the end of October, 1997, so we have not had long to improve the process of distribution. We expect that your copies will arrive in much more timely fashion in the future.

\section{Zhang Hongren \\ Editor}

